\title{
Current Perspectives on Imaging Cardiac Stem Cell Therapy
}

\author{
Joseph C. $\mathrm{Wu}^{1}$, M. Roselle Abraham ${ }^{2}$, and Dara L. Kraitchman ${ }^{3}$
}

${ }^{I}$ Department of Medicine (Cardiology) and Radiology, Stanford University School of Medicine, Stanford, California;

${ }^{2}$ Department of Medicine (Cardiology), Johns Hopkins University, Baltimore, Maryland; and ${ }^{3}$ Department of Radiology, Johns Hopkins University, Baltimore, Maryland

\begin{abstract}
Molecular imaging is a new discipline that makes possible the noninvasive visualization of cellular and molecular processes in living subjects. In the field of cardiovascular regenerative therapy, imaging cell fate after transplantation is a high priority in both basic research and clinical translation. For cell-based therapy to truly succeed, we must be able to track the locations of delivered cells, the duration of cell survival, and any potential adverse effects. The insights gathered from basic research imaging studies will yield valuable insights into better designs for clinical trials. This review highlights the different types of stem cells used for cardiovascular repair, the development of various imaging modalities to track their fate in vivo, and the challenges of clinical translation of cardiac stem cell imaging in the future.
\end{abstract}

Key Words: molecular imaging; cardiovascular disease; stem cells

J Nucl Med 2010; 51:128S-136S

DOI: 10.2967/jnumed.109.068239

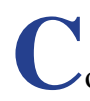

oronary artery disease is a progressive disease with high morbidity and mortality rates in the Western world. After myocardial infarction, the limited ability of the surviving cardiac cells to proliferate renders the damaged heart susceptible to unfavorable remodeling processes and morbid sequelae such as heart failure. For now, heart transplantation is the only viable treatment option for patients with end-stage heart failure. Given the persistent shortage of donor heart organs, stem cell therapy has emerged as a promising candidate for treating ischemic heart disease because it provides a virtually unlimited source of cardiomyocytes, endothelial cells, and other differentiated cell types to be used in all stages of cardiac repair $(1,2)$. Despite the potential of stem cells, several fundamental questions remain unanswered in the field of cardiac stem cell therapy. For instance, what is the longterm fate of the transplanted cells-do they integrate, proliferate, and differentiate? What are the optimal cell type, cell dosage, delivery route, and timing of injection?

Received Sep. 22, 2009; revision accepted Dec. 21, 2009.

For correspondence or reprints contact: Joseph C. Wu, 300 Pasteur

Dr., Grant S140, Stanford, CA 94305.

E-mail: joewu@stanford.edu

COPYRIGHT $\odot 2010$ by the Society of Nuclear Medicine, Inc.
Thus, the successful introduction of potentially therapeutic stem cells into patients requires concurrent techniques that provide noninvasive assessment of the survival, distribution, and pharmacokinetics of these cells. This review will present an overview of the different stem cells currently being investigated, the different imaging modalities available to track stem cells, the hurdles facing the field, and some perspectives on the future of stem cell imaging.

\section{DIFFERENT TYPES OF STEM CELLS}

There are many potential stem cell sources for myocardial repair. The 3 main types of cells are adult stem cells, embryonic stem cells (ESCs), and induced pluripotent stem (iPS) cells. At present, the most clinically applicable cell type is adult stem cells, which include skeletal myoblasts $(3,4)$, bone marrow stem cells $(5-7)$, mesenchymal stem cells (8), endothelial progenitor cells (9), and cardiac progenitor cells (10-14). Autologous skeletal myoblasts were the first cell type to be used clinically for cell-based cardiac repair (3). Skeletal myoblasts are attractive candidates because they can be cultured and expanded ex vivo from muscle biopsies, and they survive well after transplantation because of their strong resistance to ischemia. Skeletal myoblast transplantation has been shown to provide functional benefit in animal models of infarction (15), but a recent large placebo-controlled, randomized trial in humans did not demonstrate sustained efficacy as defined by the primary endpoint of global ejection fraction (16). Transplantation of bone marrow stem cells has been shown to improve heart function in animal studies $(5,17)$, and no serious complications have been reported in clinical trials to date, but long-term benefit has not been demonstrated consistently (18). Further, the mechanisms by which these stem cells exert their effects remain poorly characterized (1). In particular, the reported capacity for bone marrow stem cells to transdifferentiate into cardiomyocytes and thereby regenerate functional myocardium remains controversial $(5,17,19-21)$. Mesenchymal stem cells are another attractive therapeutic candidate because they are capable of multilineage differentiation (22) as well as possessing reported immunoprivilege status (23). In large-animal models, allogeneic porcine mesenchymal stem cells have 
been shown to reduce infarct size, increase ejection fraction, and improve myocardial blood flow (24). There are ongoing clinical trials using both autologous and allogeneic mesenchymal stem cell transplantation for myocardial regeneration (25). Endothelial progenitor cells are typically defined as cells that show endothelial characteristics, including uptake of Dil-acetylated low-density lipoprotein, and the expression of typical endothelial marker proteins including vascular endothelial growth factor receptor-2 (VEGFR-2/KDR), endoglin (CD105), von Willebrand factor, and platelet endothelial cell adhesion molecule-1 (CD31). Endothelial progenitor cells have also been used in clinical trials involving patients with chronic left ventricular dysfunction, although the beneficial effect was less than that for bone marrow stem cells (26). More recently, several studies have confirmed the presence of resident cardiac progenitor cells in the myocardium (1014). These cardiac progenitor cells can be isolated and expanded ex vivo and can also differentiate into cardiomyocytes, smooth muscle cells, and endothelial cells under the appropriate culturing conditions. Clinical trials involving cardiac progenitor cells began in 2009 .

Besides adult stem cells, another potential source of therapeutic cells is ESCs. ESCs are capable of pluripotent differentiation into all 3 germ layers (ectoderm, mesoderm, and ectoderm), whereas most adult stem cells are capable only of multipotent or unipotent differentiation (27). ESCs are also capable of unlimited self-renewal, whereas most adult stem cells have a limited capacity to divide and eventually become senescent-a phenomenon commonly known at the Hayflick limit (28). ESC-derived cardiomyocytes $(29,30)$ and ESC-derived endothelial cells $(31,32)$ have been shown to improve cardiac function after transplantation in rodent models of myocardial infarction. However, significant hurdles must be overcome before future clinical trials can take place, because of the issues of potential immunogenicity $(33,34)$ and tumorigenicity $(35,36)$, not to mention the ethical and political controversies associated with ESC research in the United States.

Unlike ESCs, iPS cells avoid the ethical and political problems because they are derived from the patient's own autologous cell source (37). iPS cells can be reprogrammed from human fibroblasts into an ESC-like phenotype using different transcription factors such as Oct 4, Sox 2, Nanog, Klf4, Lin 28, and c-Myc as originally described independently by Yamanaka (38) and Thomson (39). Besides the patient's skin cells, other starting cell sources can be keratinocytes (40), blood (41), or fat stromal cells (42). Similar to ESC-derived cardiomyocytes, iPS cells have been differentiated into cardiomyocytes (43), and injections of human iPS cells into immunocompetent mice (44) with myocardial infarction have been shown to improve cardiac function. In summary, several cell types exist with potential for cardiovascular repair. Molecular imaging will likely play an important role in improving our understanding of their safety and efficacy under a preclinical model and eventually in clinical settings in the future.

\section{IMAGING TECHNOLOGIES FOR TRACKING STEM CELLS}

Two primary methods have emerged for stem cell labeling using noninvasive imaging. Direct labeling strategies using radioactive tracers and iron particles have been the most widely adapted for radionuclide imaging and MRI, respectively (45-52). Fewer reports have been published using nanoparticles such as quantum dots $(53,54)$. The second major method of stem cell labeling uses the transfection of stem cells to express a protein, receptor, or enzyme that can be detected by noninvasive reporter gene imaging. That technique has been performed primarily using SPECT (55) and PET (56-61). However, a few examples using MRI $(62,63)$, ultrasound (64), and other imaging modalities (65-67) have been used in preclinical studies. The primary advantage of direct labeling techniques is the simplicity and therefore the minimal manipulation of the cells that is required. The primary disadvantage of direct labeling techniques is that the label can become physically decoupled from the stem cell such that the detection of the label may no longer represent engrafted stem cells. In contrast, the primary advantage of reporter gene techniques is that the reporter gene is usually detected only in living cells. In addition, if the cells are rapidly dividing, the reporter gene should be imparted to the daughter cells such that the stem cells can still be detected over time in later generations. However, transfection of the cells with reporter genes is a more arduous process than direct labeling methods.

Each imaging modality has specific advantages and disadvantages with respect to delivery and tracking of stem cells for cardiovascular applications (Fig. 1). Radionuclide imaging techniques excel at detecting small numbers of cells because they lack background signals. However, both anatomic imaging and interactivity are poor with radionuclide. Optical imaging techniques are well suited for reporter gene techniques in small animals but suffer from the inability to detect cells deep within the body, limiting their clinical applicability. MRI provides superb anatomic detail of soft tissue but lacks the sensitivity to detect small numbers of cells. Interventional techniques with MRI are still in the developmental stages because of the need to create MRI-compatible devices. Nevertheless, the lack of ionizing radiation with MRI is another advantage over conventional radiographic and radionuclide techniques.

Although echocardiography provides a safe, noninvasive, and inexpensive method to rapidly evaluate cardiac function, methods to label stem cells for tracking are only now being explored. Contrast-enhanced ultrasound techniques using site-specific microbubbles have been applied for imaging angiogenesis and more recently for imaging cell engraftment as well (68). In a recent study, Kuliszewski et al. transfected bone marrow-derived endothelial progenitor 
FIGURE 1. Schematic for noninvasive imaging of stem cell fate in myocardium. Four different techniques include magnetic particle labeling, radionuclide labeling, quantum dot labeling, and reporter gene labeling. First 3 techniques are considered physical labeling, whereas last technique is considered genetic labeling. SPIO = superparamagnetic iron oxide; IFP = iron fluorescent particles. (Reprinted with permission of (45).)

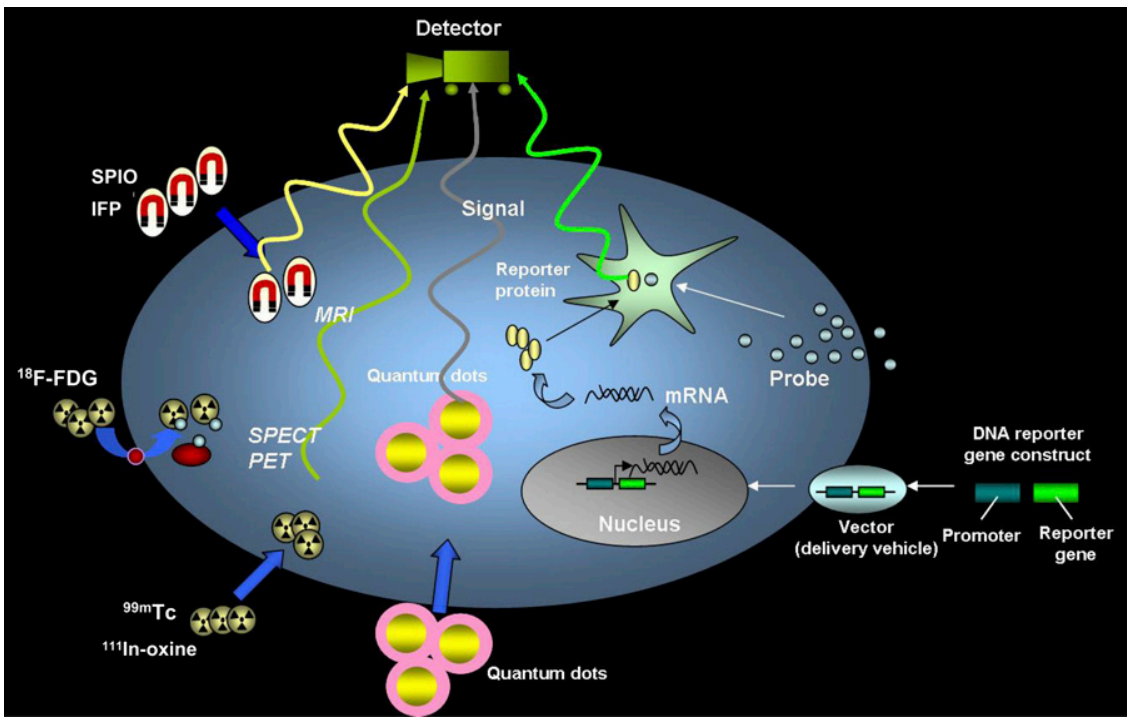

cells to express a unique marker protein $(\mathrm{H}-2 \mathrm{Kk})$ on the cell surface (64). Through attachment of the monoclonal antibody against $\mathrm{H}-2 \mathrm{Kk}$ onto the outer surface of microbubbles, endothelial progenitor cell-targeted microbubbles were created. In vivo contrast-enhanced ultrasound imaging of endothelial progenitor cells engrafted into the vasculature within Matrigel (BD Biosciences) plugs was demonstrated. The real-time interactivity of echocardiography and lack of ionizing radiation favor the development of this imaging modality for stem cell delivery and tracking.
Similarly, the real-time interactivity of x-ray angiography has made it the method of choice for minimally invasive cardiovascular stem cell therapeutic trials. But the high toxicity of most radiopaque contrast agents has limited the feasibility of stem cell tracking. New emerging strategies may be able to overcome these problems. However, at present, other imaging modalities as described above have been more extensively developed both for potential translation to the clinical realm and for optimizing stem cell therapeutic regimes.
FIGURE 2. (A-C) Detection of ${ }^{18} \mathrm{~F}$ FDG-labeled cardiac-derived stem cells (CDCs) in rat heart by small-animal PET/ CT. CDCs were labeled with $74 \mathrm{kBq}$ of ${ }^{18} \mathrm{~F}-\mathrm{FDG}$ per milliliter and injected intramyocardially after ligation of mid left anterior descending coronary artery. PET was performed immediately after cell transplantation. Myocardium (green) was delineated by intravenous injection of $37 \mathrm{MBq}$ of ${ }^{13} \mathrm{~N}-\mathrm{NH}_{3}$. Cells (red) were visualized within perfusion deficit by PET. Transverse (A), coronal $(B)$, and sagittal $(C)$ image orientations are shown. (D-F) SPECT/CT of sodiumiodide symporter-transduced CDCs in rat heart. CDCs were transduced with lentivirus expressing sodium-iodide symporter driven by constitutively active promoter, cytomegalovirus, and injected intramyocardially after ligation of mid left anterior descending coronary artery. SPECT/CT dual-isotope imaging was performed $24 \mathrm{~h}$ after cell transplantation. Myocardium (green) was delineated by intravenous injection of ${ }^{201} \mathrm{TI}$. Transplanted cells (red) were identified within perfusion deficit by SPECT after intravenous injection of $99 \mathrm{mT}$. Transverse (D), coronal (E), and sagittal (F) image orientations are shown.
A

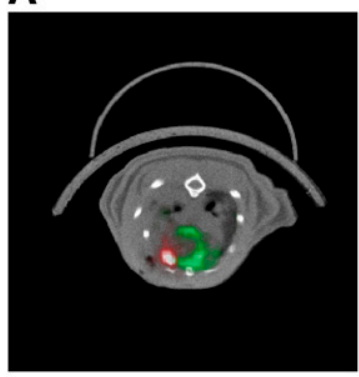

D

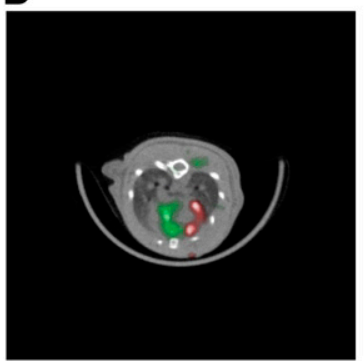

B

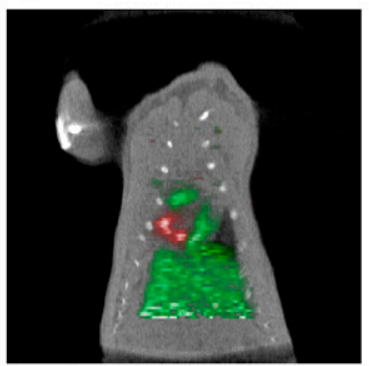

E

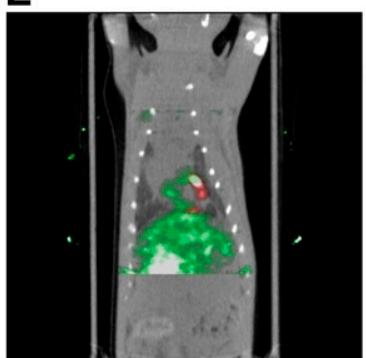

C

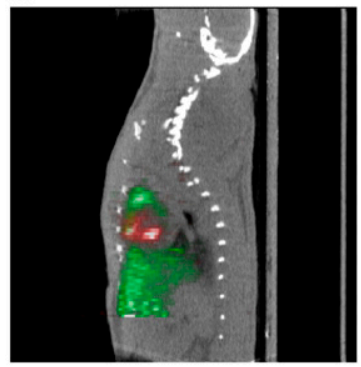

$\mathbf{F}$

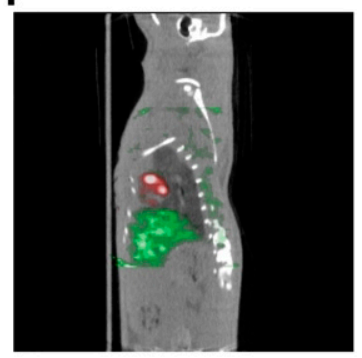


A

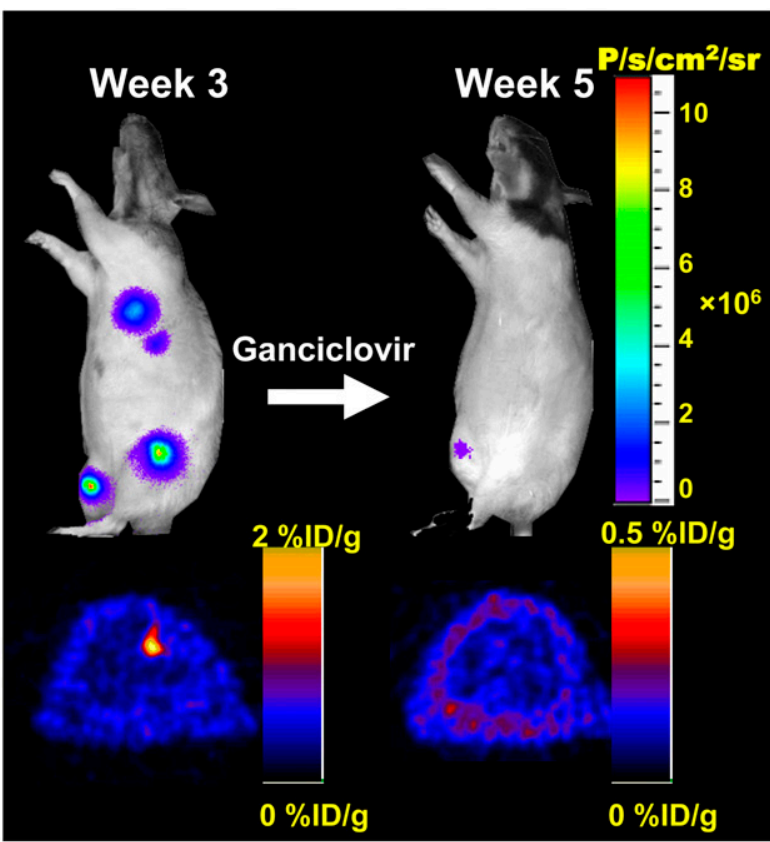

B

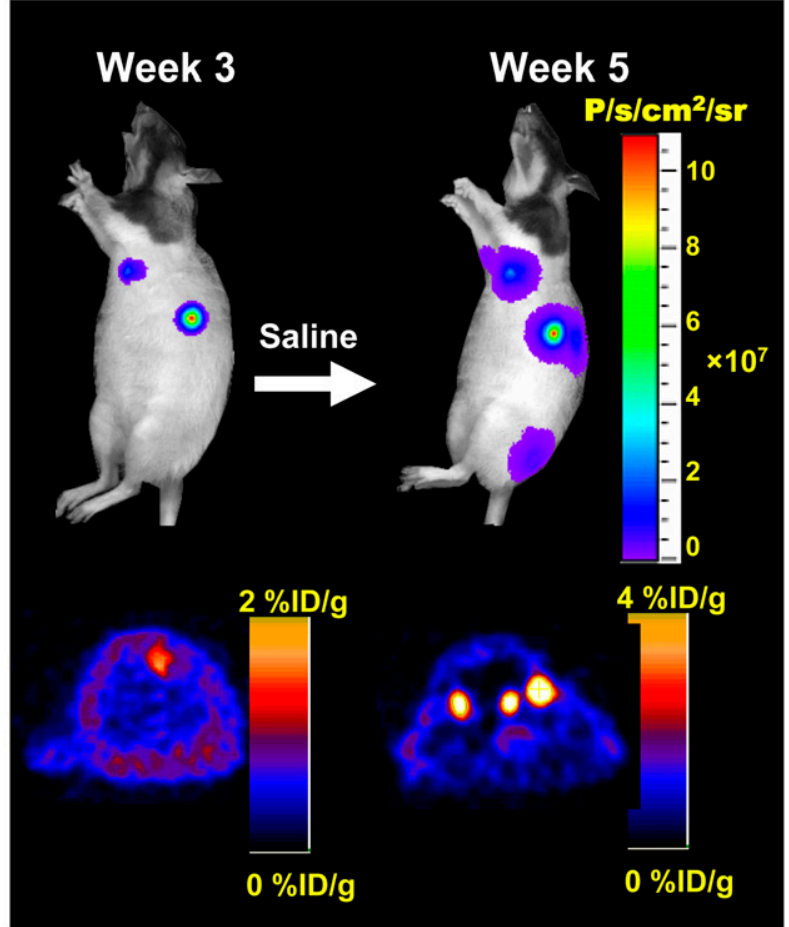

FIGURE 3. Ablation of teratoma formation with HSVttk as both PET reporter gene and suicide gene. (A) Immunodeficient animals were injected with undifferentiated mouse ESCs stably expressing triple-fusion reporter gene construct (Fluc-mRFP-HSVttk). Treatment of control animals with saline resulted in formation of multiple teratomas by week 5. (B) In contrast, study animals treated with ganciclovir (50 $\mathrm{mg} / \mathrm{kg}$ of body weight) for $2 \mathrm{wk}$ showed abrogation of both bioluminescence and PET signals. (Reprinted with permission of (56).)
IMAGING ADULT STEM CELLS: OPPORTUNITIES AND CHALLENGES

In all studies of adult stem cell transplantation, the gain in cardiac function, when identified, has been modest, with reported increases of left ventricular ejection fraction versus placebo usually being about 5\% (26,69-71). Possible reasons for the marginal benefit are low transplanted cell engraftment and low levels of differentiation into functioning cardiac myocytes. Augmenting transplanted cell engraftment could improve long-term functional benefit by increased differentiation of stem cells into cardiac myocytes, increased recruitment of endogenous stem cells, and beneficial effects on surviving cardiac myocytes via paracrine mechanisms. A combination of fundamental work on the determinants of cell engraftment in the acute and chronic infarct settings, and molecular imaging techniques that provide information about cell fate, cardiac function, and infarct size, is needed to maximize cardiac regeneration and minimize the risk of complications such as ventricular arrhythmias (16,72-75). In vitro studies indicate that cell type, cell number, and the underlying architecture are important determinants of arrhythmogenesis $(76,77)$. Hence, quantification and localization of cell engraftment using molecular imaging techniques would be useful in minimizing adverse events in clinical studies of cell transplantation.

Although MRI, bioluminescence, and nuclear imaging have been used to track adult stem cells in vivo after transplantation, only nuclear and bioluminescence imaging allow quantification of engraftment. Recently, preclinical bioluminescence imaging studies have been performed for assessment of important clinical questions such as the optimal timing of stem cell delivery (78), direct comparison of various stem cell types (79-81), and determination of the temporal kinetics of bone marrow stem cell homing after systemic delivery (67). Bioluminescence imaging, however, is limited to small animals. PET of ${ }^{18} \mathrm{~F}-\mathrm{FDG}-$ labeled stem cells is an attractive option because PET permits quantification of engraftment in vivo as well as translation into large-animal models and humans. However, because the half-life of ${ }^{18} \mathrm{~F}$ is about $110 \mathrm{~min}$, this technique can be used only to interrogate acute biodistribution and cell retention after transplantation. Studies using a variety of techniques, including direct cell radiolabeling, genetic labeling with reporter genes, and real-time quantitative polymerase chain reaction, have revealed that acute myocardial cell retention was less than $10 \%$ with $48 \mathrm{~h}$ irrespective of the cell type and delivery route $(45,46,49,72,82-84)$. An improved understanding of the determinants and functional consequences of varying acute cell retention is needed to design new, effective cell delivery strategies.

In a recent study, PET of ${ }^{18} \mathrm{~F}-\mathrm{FDG}-$ labeled cardiac stem cells (Fig. 2) in a rat model of myocardial infarction revealed that large numbers of intramyocardially injected cells were trapped in the lungs acutely, an effect that was 


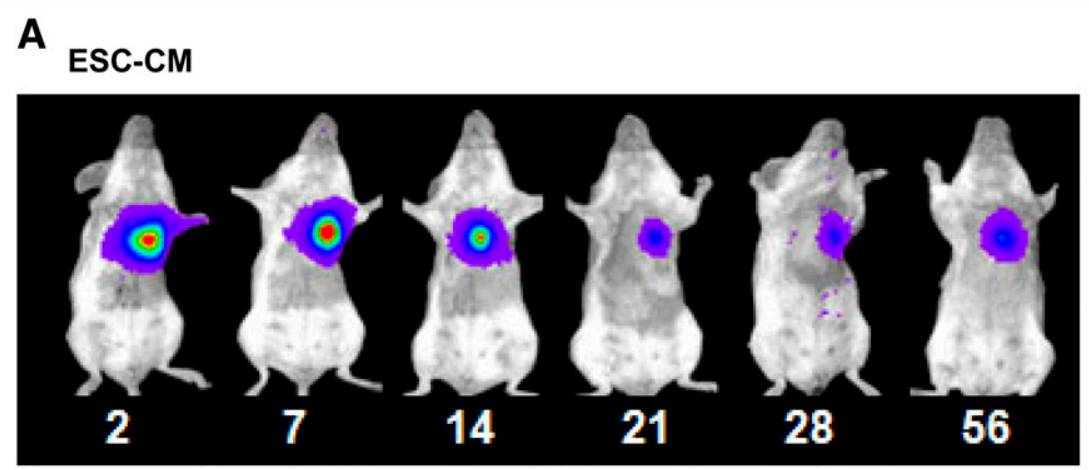

Days after transplantation

\section{B}

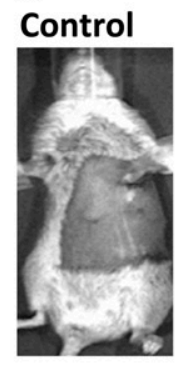

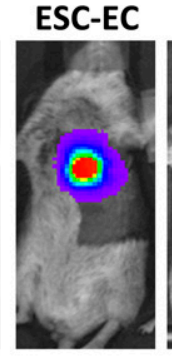

Day 2

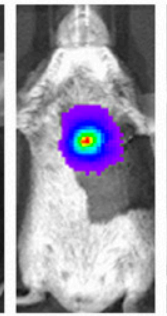

Day 7
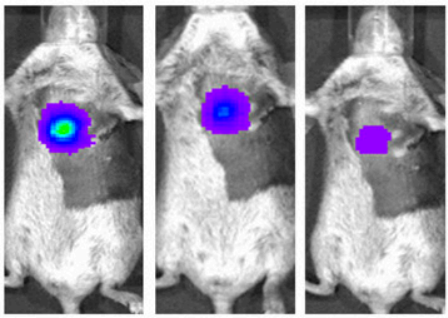

Week 2
Week 4

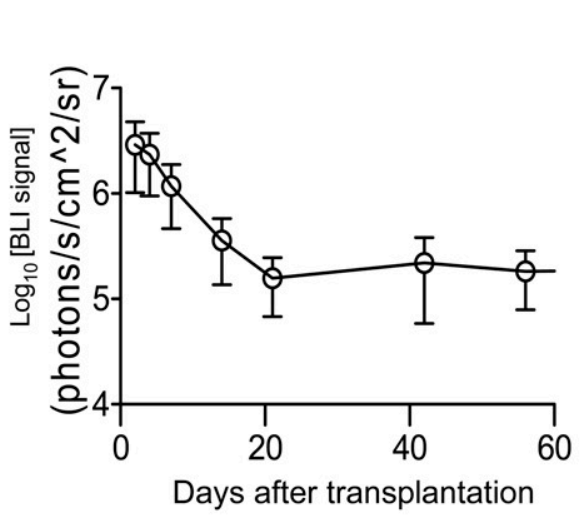

Days after transplantation

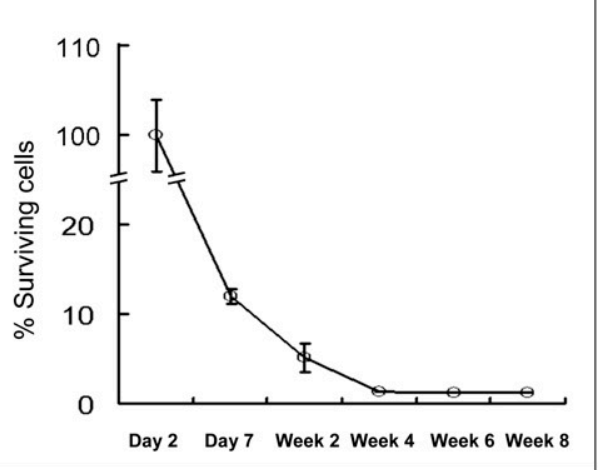

FIGURE 4. Imaging fate of transplanted ESC-derived cardiomyocytes and ESC-derived endothelial cells. (A) Human ESCderived cardiomyocytes stably expressing Fluc-eGFP double-fusion reporter gene were injected into ischemic myocardium of immunodeficient SCID mice. Longitudinal bioluminescence imaging showed that signal activity fell drastically within first 3 wk of transplantation and remained stable thereafter, with no evidence of tumorigenesis. (Reprinted with permission of (29).) (B) Mouse ESC-derived endothelial cells stably expressing Fluc-eGFP double fusion reporter gene were injected into ischemic myocardium of syngeneic SV129 mice. Longitudinal bioluminescence imaging showed similar pattern of acute donor cell loss, with about $1 \%$ signal intensity (relative to day 2) at $8 \mathrm{wk}$. Control animals injected with phosphate-buffered saline showed no imaging signals, as expected. (Reprinted with permission of (31).) CM = cardiomyocyte; EC = endothelial cell.

more pronounced during ischemia-reperfusion (85). Another study using the same animal model indicated that acute myocardial cell retention could be doubled by decreasing the ventricular rate with adenosine administration or by epicardial application of fibrin glue (86). Together, these results suggest that the coronary microvasculature and contractility play an important role in acute cell retention even after intramyocardial cell injections. Future studies incorporating advances in tissue engineering and PET have the potential of greatly improving transplanted cell retention and possibly the functional consequences of cell therapy.

Important insights into in vivo stem cell biology can be gleaned from longitudinal interrogation of cell fate after transplantation. A recent study in a rat model of cell transplantation used the human sodium-iodide symporter gene as a reporter gene for longitudinal stem cell tracking by SPECT and PET (Fig. 2B) (84). Sodium-iodide symporter transports iodine in conjunction with sodium ions into cells and is highly expressed in the thyroid, salivary gland, choroid plexus, stomach, and lactating mammary gland (87) but is not expressed in the heart, thus permitting detection of transplanted cells expressing this gene by PET or SPECT, after intravenous administration of iodine or pertechnetate $\left({ }^{99 \mathrm{~m}} \mathrm{Tc}\right)$. The main significance of this study lies in the potential for clinical translation because pertechnetate SPECT is a widely available, clinically approved imaging modality. The principal downside of using this reporter gene for cell tracking is low signal in the acute setting after cell transplantation, which could be related to edema at the injection site or impaired energetics in the injected cells.

\section{IMAGING EMBRYONIC STEM CELLS: OPPORTUNITIES AND CHALLENGES}

As stated previously, pluripotent stem cells (e.g., ESCs and iPS cells) have generated significant interest because of their self-renewing capacity and pluripotent potential. In general, the 3 stages of cardiac development can be broadly categorized as undifferentiated ESCs, differentiated beating embryoid bodies, and differentiated ESC-derived cardiomyocytes. In 2006, the initial proof-of-principle study used 


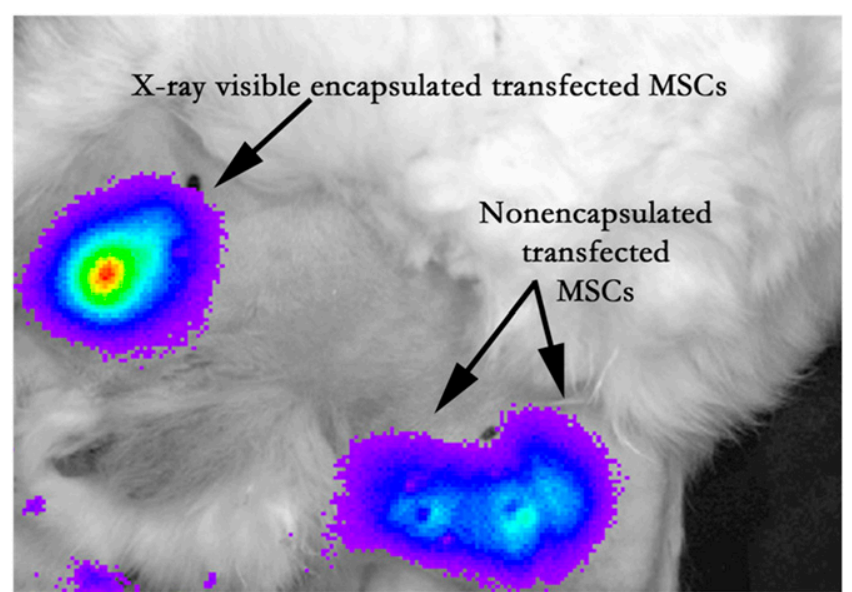

FIGURE 5. Bioluminescence imaging after intramuscular injection in medial thigh of rabbit model of peripheral arterial disease provides ability to assess cell viability in vivo in $\mathrm{x}$-ray-visible encapsulated mesenchymal stem cells, similar to nonencapsulated mesenchymal stem cells. (Reprinted with permission of (101).)

undifferentiated murine ESCs stably expressing a triplefusion reporter gene construct with firefly luciferase (Fluc; bioluminescence), monomeric red fluorescent protein (mRFP; fluorescence), and herpes simplex virus truncated thymidine kinase (HSVttk; PET reporter gene) to track cell fate in vivo (56). Both bioluminescence and PET imaging showed that undifferentiated ESCs are capable of causing both intracardiac and extracardiac teratomas (i.e., tumors consisting of all 3 germ layers), which can be ablated by treatment with ganciclovir that targets HSVttk-expressing cells (Fig. 3). A follow-up study has shown that injection of mouse ESC-derived beating embryoid bodies can also lead to teratoma formation with delayed onset (88). Indeed, intramyocardial injections of as few as 100,000 human ESCs have been shown to cause teratoma formation in immunodeficient mice (36).
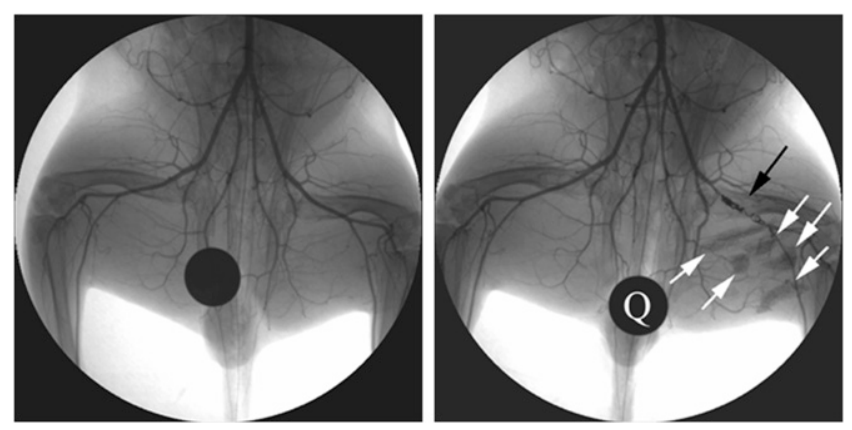

FIGURE 6. X-ray angiogram of peripheral hind limb of rabbit before intervention (left) and after creation of femoral artery occlusion via platinum coil (black arrow). X-ray-visible microencapsulated stem cells injected intramuscularly in medial thigh appear as radiopacities (white arrows). Quarter (Q) is used for reference measurements. (Reprinted with permission of (102).)
Together, these studies indicate that highly purified ESCderived cardiomyocytes are required to minimize the risk of tumor formation for cell-based treatment of myocardial dysfunction. Several studies have shown that transplantation of ESC-derived cardiomyocytes can lead to improved cardiac function $(29,30,89)$. However, analysis with bioluminescence imaging indicates that about $90 \%$ of cells die within the first 3 wk of delivery, which may be one reason why only short-term improvement of cardiac function was observed (Fig. 4) (29). Similarly, limited long-term survival of ESC-derived endothelial cells was seen after injections into both the heart (31) and skeletal muscles (90). Thus, the problem of donor cell death is particularly troublesome and may limit the overall efficacy of stem cell-based therapy, making continuing investigations into cell fate monitoring with new imaging technologies essential.

Another hurdle facing clinical transplantation of human ESCs is the potential immunologic barrier (91). The immune response generated after transplantation is directed toward alloantigens, which are antigens presenting on the cell surface that are considered nonself by the recipient immune system (27). Solutions that reduce or eliminate the potential immunologic response to transplanted allogeneic human ESCs are needed and are reviewed elsewhere (92). Possible strategies to minimize rejection of human ESC transplants include forming human leukocyte antigen isotype human ESC-line banks and creating a universal donor cell by genetic modification. In the meantime, immunosuppressive drugs will be needed. Indeed, the first proposed clinical trial of human ESC therapy involving injections of differentiated neuronal cells into patients with acute spinal cord injury will also involve immunosuppression. However, using longitudinal bioluminescence imaging analysis, Swijnenburg et al. have reported that the single-drug regimen with mycophenolate mofetil, sirolimus, or tacrolimus was not effective in preventing rejection of human ESCs in immunocompetent mice (34). The combination of tacrolimus and sirolimus was found to prolong human ESC survival modestly to about $4 \mathrm{wk}$. Thus, further investigations are clearly needed in this area, along with the development of iPS cells, which in theory should avoid the immunogenicity problem because the cells are derived from the patients themselves (37).

\section{CHALLENGES IN CLINICAL TRANSLATION}

To date, most academic centers have focused on developing new methodologies for stem cell labeling and tracking and may lack the resources to make goodmanufacturing-practice products or perform extensive safety and efficacy testing. The U.S. Food and Drug Administration (FDA) has developed a framework for the regulation of stem cells (93). Many techniques are being developed using clinically approved radiotracers or contrast agents for labeling stem cells. However, because the cellular product that will be labeled is typically different 
FIGURE 7. PET/CT reporter gene imaging of mesenchymal stem cells in porcine heart. Mesenchymal stem cells were transduced with adenovirus containing cytomegalovirus promoter driving HSVtk reporter gene in vitro, followed by transplantation into porcine myocardium through left thoracotomy. Cells could then be visualized after 9-(4-18 F-fluoro-3-[hydroxymethyl]butyl)guanine injection, seen in this reconstructed image of left ventricle taken $4 \mathrm{~h}$ after intravenous administration of PET reporter probe. Arrows show localiza-

A

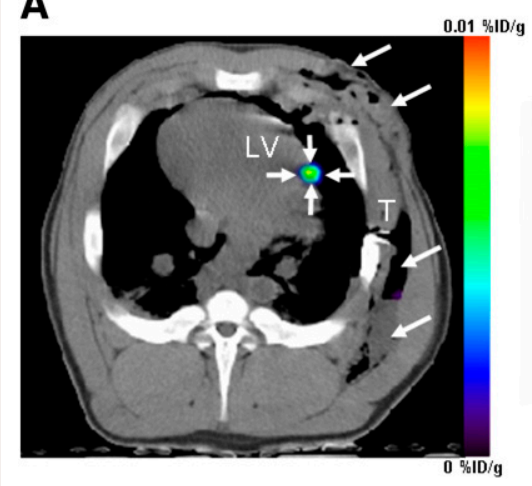

B

$\mathrm{R}$ L

tion of cells at injection site in heart.

\%ID = percentage injected dose; LV = left ventricle; $\mathrm{T}=$ thoracotomy site. (Reprinted with permission of (103).)

from the FDA-approved application (e.g., ${ }^{111}$ In-oxine of lymphocytes), or the route of administration (e.g., intracoronary) may be different, the regulatory hurdles can be quite complex. To obtain an investigational new drug application, one would have to seek approval for the stem cell product and also meet the guidelines for radiopharmaceuticals or contrast agents. Reporter gene transfection of cells is similarly covered by relevant FDA guidelines that must be met.

Beyond adherence to FDA guidelines, there are other major hurdles to clinical translation. Frequently, stem cells for cardiovascular applications are administered directly to the myocardium either using a minimally invasive transendocardial approach or during coronary artery bypass surgery. Both techniques could potentially use new devices to inject the stem cells. Although devices for gene therapy applications including stem cell delivery have been developed by several small companies, the lack of preclinical studies showing high efficacy has tempered the enthusiasm of major vendors to foster development of such devices. In particular, the complexity and cost of device development can be prohibitive for new methods such as MRI guidance or electromechanical mapping.

In addition to the device and stem cell approval process by the FDA, there is the question of which stem cell products are to be used in preclinical animal studies to demonstrate efficacy. Because the final product that will be used in patients will presumably be of human origin, should the animal studies be performed using autologous or allogeneic stem cells? Should human stem cells be used in an immunosuppressed animal, and if so, which specific regimen of drugs should be used? It is possible that immunosuppressed animals could yield different results from those in immunocompetent animals. Furthermore, so far most cardiac stem cell trials have used interventional techniques for stem cell delivery, that is, intracoronary or transmyocardial routes $(7,71,94-97)$. Thus, whether preclinical work using labeled stem cells should focus on animals large enough to replicate these preferred delivery methods must also be determined.
To this end, a hybrid technique has exploited microencapsulation techniques that provide immunoprotection of transplanted donor cells (98) with x-ray-based delivery methods for cell tracking. Radiopaque agents can be added to the microcapsule to enable visualization by $\mathrm{x}$-ray fluoroscopic and CT imaging $(99,100)$. The incorporation of high concentrations of radiopaque agent in the microcapsule without inducing toxicity or detrimental effects to the porous microcapsule is an advantage of the system. $\mathrm{X}$-ray-visible microcapsules can then be used to deliver stem cells during cardiovascular interventions (Figs. 5 and 6) $(101,102)$. Like direct labeling techniques, microcapsule tracking does not indicate whether the stem cells remain viable. Such a technique could be used in combination with reporter gene transfection of stem cells to deliver stem cells using conventional $\mathrm{x}$-ray imaging platforms with follow-up examination by PET/CT or SPECT/CT (Fig. 7) (103).

\section{CONCLUSION}

Although current imaging tools have illuminated different facets of stem cell biology in vivo, further efforts are needed by stem cell biologists and imaging experts to develop, validate, and accelerate progress in this field. Stem cell tracking requires high sensitivity and high spatial resolution; at present, no single imaging modality is perfect in all aspects. Future efforts should continue focusing on the development of multimodality imaging approaches capable of answering biologically relevant questions and clinical translation.

\section{ACKNOWLEDGMENT}

This work was supported in part by R21HL09145301A1S1 and RC1HL099117.

\section{REFERENCES}

1. Laflamme MA, Murry CE. Regenerating the heart. Nat Biotechnol. 2005;23:845-856.

2. Wollert KC, Drexler H. Clinical applications of stem cells for the heart. Circ Res. 2005;96:151-163. 
3. Menasche P, Hagege AA, Vilquin JT, et al. Autologous skeletal myoblast transplantation for severe postinfarction left ventricular dysfunction. J Am Coll Cardiol. 2003;41:1078-1083.

4. Taylor DA, Atkins BZ, Hungspreugs $P$, et al. Regenerating functional myocardium: improved performance after skeletal myoblast transplantation. Nat Med. 1998;4:929-933.

5. Orlic D, Kajstura J, Chimenti S, et al. Bone marrow cells regenerate infarcted myocardium. Nature. 2001;410:701-705.

6. Jackson KA, Majka SM, Wang H, et al. Regeneration of ischemic cardiac muscle and vascular endothelium by adult stem cells. J Clin Invest. 2001; 107:1395-1402.

7. Wollert KC, Meyer GP, Lotz J, et al. Intracoronary autologous bone-marrow cell transfer after myocardial infarction: the BOOST randomised controlled clinical trial. Lancet. 2004;364:141-148.

8. Amado LC, Saliaris AP, Schuleri KH, et al. Cardiac repair with intramyocardial injection of allogeneic mesenchymal stem cells after myocardial infarction. Proc Natl Acad Sci USA. 2005;102:11474-11479.

9. Assmus B, Schachinger V, Teupe C, et al. Transplantation of Progenitor Cells and Regeneration Enhancement in Acute Myocardial Infarction (TOPCAREAMI). Circulation. 2002;106:3009-3017.

10. Beltrami AP, Barlucchi L, Torella D, et al. Adult cardiac stem cells are multipotent and support myocardial regeneration. Cell. 2003;114:763-776.

11. Dawn B, Stein AB, Urbanek $\mathrm{K}$, et al. Cardiac stem cells delivered intravascularly traverse the vessel barrier, regenerate infarcted myocardium, and improve cardiac function. Proc Natl Acad Sci USA. 2005;102:3766-3771.

12. Messina E, De Angelis L, Frati G, et al. Isolation and expansion of adult cardiac stem cells from human and murine heart. Circ Res. 2004;95:911-921.

13. Oh H, Bradfute SB, Gallardo TD, et al. Cardiac progenitor cells from adult myocardium: homing, differentiation, and fusion after infarction. Proc Natl Acad Sci USA. 2003;100:12313-12318.

14. Smith RR, Barile L, Cho HC, et al. Regenerative potential of cardiospherederived cells expanded from percutaneous endomyocardial biopsy specimens. Circulation. 2007;115:896-908

15. Koh GY, Klug MG, Soonpaa MH, Field LJ. Differentiation and long-term survival of C2C12 myoblast grafts in heart. J Clin Invest. 1993;92:1548-1554.

16. Menasche P, Alfieri O, Janssens S, et al. The Myoblast Autologous Grafting in Ischemic Cardiomyopathy (MAGIC) trial: first randomized placebo-controlled study of myoblast transplantation. Circulation. 2008;117:1189-1200.

17. Yoon YS, Wecker A, Heyd L, et al. Clonally expanded novel multipotent stem cells from human bone marrow regenerate myocardium after myocardial infarction. J Clin Invest. 2005;115:326-338.

18. Rosenzweig A. Cardiac cell therapy: mixed results from mixed cells. $N$ Engl J Med. 2006;355:1274-1277.

19. Murry CE, Soonpaa MH, Reinecke H, et al. Haematopoietic stem cells do not transdifferentiate into cardiac myocytes in myocardial infarcts. Nature. 2004;428:664-668.

20. Pittenger MF, Martin BJ. Mesenchymal stem cells and their potential as cardiac therapeutics. Circ Res. 2004;95:9-20.

21. Balsam LB, Wagers AJ, Christensen JL, Kofidis T, Weissman IL, Robbins RC. Haematopoietic stem cells adopt mature haematopoietic fates in ischaemic myocardium. Nature. 2004;428:668-673.

22. Pittenger MF, Mackay AM, Beck SC, et al. Multilineage potential of adult human mesenchymal stem cells. Science. 1999;284:143-147.

23. Aggarwal S, Pittenger MF. Human mesenchymal stem cells modulate allogeneic immune cell responses. Blood. 2005;105:1815-1822.

24. Quevedo HC, Hatzistergos KE, Oskouei BN, et al. Allogeneic mesenchymal stem cells restore cardiac function in chronic ischemic cardiomyopathy via trilineage differentiating capacity. Proc Natl Acad Sci USA. 2009;106:14022_ 14027.

25. Hare JM, Chaparro SV. Cardiac regeneration and stem cell therapy. Curr Opin Organ Transplant. 2008;13:536-542.

26. Assmus B, Honold J, Schachinger V, et al. Transcoronary transplantation of progenitor cells after myocardial infarction. N Engl J Med. 2006;355:1222-1232.

27. van der Bogt KE, Swijnenburg RJ, Cao F, Wu JC. Molecular imaging of human embryonic stem cells: keeping an eye on differentiation, tumorigenicity and immunogenicity. Cell Cycle. 2006;5:2748-2752.

28. Hayflick L. The establishment of a line (WISH) of human amnion cells in continuous cultivation. Exp Cell Res. 1961;23:14-20.

29. Cao F, Wagner RA, Wilson KD, et al. Transcriptional and functional profiling of human embryonic stem cell-derived cardiomyocytes. PLoS One. 2008; 3:e3474.

30. Laflamme MA, Chen KY, Naumova AV, et al. Cardiomyocytes derived from human embryonic stem cells in pro-survival factors enhance function of infarcted rat hearts. Nat Biotechnol. 2007;25:1015-1024.
31. Li Z, Wu JC, Sheikh AY, et al. Differentiation, survival, and function of embryonic stem cell derived endothelial cells for ischemic heart disease. Circulation. 2007;116(11, suppl)I46-I54.

32. Li Z, Wilson $\mathrm{KD}$, Smith $\mathrm{BR}$, et al. Functional and transcriptional characterization of human embryonic stem cell-derived endothelial cells for treatment of mycoardial infarction. PLoS One. 2009;4(12):e8443.

33. Swijnenburg RJ, Schrepfer S, Cao F, et al. In vivo imaging of embryonic stem cells reveals patterns of survival and immune rejection following transplantation. Stem Cells Dev. 2008;17:1023-1029.

34. Swijnenburg RJ, Schrepfer S, Govaert JA, et al. Immunosuppressive therapy mitigates immunological rejection of human embryonic stem cell xenografts. Proc Natl Acad Sci USA. 2008;105:12991-12996.

35. Cao F, Van Der Bogt KE, Sadrzadeh A, et al. Spatial and temporal kinetics of teratoma formation from murine embryonic stem cell transplantation. Stem Cells Dev. 2007;16:1-9.

36. Lee AS, Tang C, Cao F, et al. Effects of cell number on teratoma formation by human embryonic stem cells. Cell Cycle. 2009;8:2608-2612.

37. Sun N, Longaker MT, Wu JC. Human iPS cell-based therapy: considerations before clinical applications. Cell Cycle. 2010;9:1-6.

38. Takahashi K, Tanabe K, Ohnuki M, et al. Induction of pluripotent stem cells from adult human fibroblasts by defined factors. Cell. 2007;131:861-872.

39. Yu J, Vodyanik MA, Smuga-Otto K, et al. Induced pluripotent stem cell lines derived from human somatic cells. Science. 2007;318:1917-1920.

40. Aasen T, Raya A, Barrero MJ, et al. Efficient and rapid generation of induced pluripotent stem cells from human keratinocytes. Nat Biotechnol. 2008;26: 1276-1284.

41. Loh YH, Agarwal S, Park IH, et al. Generation of induced pluripotent stem cells from human blood. Blood. 2009;113:5476-5479.

42. Sun N, Panetta NJ, Gupta DM, et al. Feeder-free derivation of induced pluripotent stem cells from adult human adipose stem cells. Proc Natl Acad Sci USA. 2009;106:15720-15725.

43. Zhang J, Wilson GF, Soerens AG, et al. Functional cardiomyocytes derived from human induced pluripotent stem cells. Circ Res. 2009;104:e30-e41.

44. Nelson TJ, Martinez-Fernandez A, Yamada S, Perez-Terzic C, Ikeda Y, Terzic A. Repair of acute myocardial infarction by human stemness factors induced pluripotent stem cells. Circulation. 2009;120:408-416.

45. Zhang SJ, Wu JC. Comparison of imaging techniques for tracking cardiac stem cell therapy. J Nucl Med. 2007;48:1916-1919.

46. Aicher A, Brenner W, Zuhayra M, et al. Assessment of the tissue distribution of transplanted human endothelial progenitor cells by radioactive labeling. Circulation. 2003;107:2134-2139.

47. Chin BB, Nakamoto Y, Bulte JW, Pittenger MF, Wahl R, Kraitchman DL. ${ }^{111}$ In oxine labelled mesenchymal stem cell SPECT after intravenous administration in myocardial infarction. Nucl Med Commun. 2003;24: 1149-1154.

48. Jin Y, Kong H, Stodilka RZ, et al. Determining the minimum number of detectable cardiac-transplanted ${ }^{111}$ In-tropolone-labelled bone-marrowderived mesenchymal stem cells by SPECT. Phys Med Biol. 2005;50: 4445-4455.

49. Kraitchman DL, Tatsumi M, Gilson WD, et al. Dynamic imaging of allogeneic mesenchymal stem cells trafficking to myocardial infarction. Circulation. 2005;112:1451-1461.

50. Bindslev L, Haack-Sørensen M, Bisgaard K, et al. Labelling of human mesenchymal stem cells with indium-111 for SPECT imaging: effect on cell proliferation and differentiation. Eur J Nucl Med Mol Imaging. 2006;33:11711177.

51. Doyle B, Kemp BJ, Chareonthaitawee $\mathrm{P}$, et al. Dynamic tracking during intracoronary injection of ${ }^{18} \mathrm{~F}$-FDG-labeled progenitor cell therapy for acute myocardial infarction. J Nucl Med. 2007;48:1708-1714.

52. Zhou R, Thomas DH, Qiao H, et al. In vivo detection of stem cells grafted in infarcted rat myocardium. J Nucl Med. 2005;46:816-822.

53. Lin S, Xie X, Patel MR, et al. Quantum dot imaging for embryonic stem cells. BMC Biotechnol. 2007;7:67.

54. Michalet X, Pinaud FF, Bentolila LA, et al. Quantum dots for live cells, in vivo imaging, and diagnostics. Science. 2005;307:538-544.

55. Stodilka RZ, Blackwood KJ, Kong H, Prato FS. A method for quantitative cell tracking using SPECT for the evaluation of myocardial stem cell therapy. Nucl Med Commun. 2006;27:807-813.

56. Cao F, Lin S, Xie X, et al. In vivo visualization of embryonic stem cell survival, proliferation, and migration after cardiac delivery. Circulation. 2006;113:10051014.

57. Wu JC, Inubushi M, Sundaresan G, Schelbert HR, Gambhir SS. Positron emission tomography imaging of cardiac reporter gene expression in living rats. Circulation. 2002;106:180-183. 
58. Wu JC, Chen IY, Sundaresan G, et al. Molecular imaging of cardiac cell transplantation in living animals using optical bioluminescence and positron emission tomography. Circulation. 2003;108:1302-1305.

59. Inubushi M, Wu JC, Gambhir SS, et al. Positron-emission tomography reporter gene expression imaging in rat myocardium. Circulation. 2003;107: 326-332.

60. Miyagawa M, Anton M, Wagner B, et al. Non-invasive imaging of cardiac transgene expression with PET: comparison of the human sodium/iodide symporter gene and HSV1-tk as the reporter gene. Eur J Nucl Med Mol Imaging. 2005;32:1108-1114.

61. Gyöngyösi M, Blanco J, Marian T, et al. Serial non-invasive in vivo positron emission tomographic (PET) tracking of percutaneously intramyocardially injected autologous porcine mesenchymal stem cells modified for transgene reporter gene expression. Circ Cardiovasc Imaging. 2008;1:94-103.

62. Gilad AA, McMahon MT, Walczak P, et al. Artificial reporter gene providing MRI contrast based on proton exchange. Nat Biotechnol. 2007;25:217-219.

63. Liu J, Cheng EC, Long RC, et al. Noninvasive monitoring of embryonic stem cells in vivo with MRI transgene reporter. Tissue Eng Part C Methods. 2009;15:739-747.

64. Kuliszewski MA, Fujii H, Liao C, et al. Molecular imaging of endothelial progenitor cell engraftment using contrast-enhanced ultrasound and targeted microbubbles. Cardiovasc Res. 2009;83:653-662.

65. Min JJ, Ahn Y, Moon S, et al. In vivo bioluminescence imaging of cord blood derived mesenchymal stem cell transplantation into rat myocardium. Ann Nucl Med. 2006;20:165-170.

66. Wilson $\mathrm{K}, \mathrm{Yu} \mathrm{J}$, Lee A, Wu JC. In vitro and in vivo bioluminescence reporter gene imaging of human embryonic stem cells. J Vis Exp. 2008;(14):pii 740.

67. Sheikh AY, Lin SA, Cao F, et al. Molecular imaging of bone marrow mononuclear cell homing and engraftment in ischemic myocardium. Stem Cells. 2007;25:2677-2684.

68. Leong-Poi H. Molecular imaging using contrast-enhanced ultrasound: evaluation of angiogenesis and cell therapy. Cardiovasc Res. 2009;84:190-200.

69. Janssens S, Dubois C, Bogaert J, et al. Autologous bone marrow-derived stemcell transfer in patients with ST-segment elevation myocardial infarction: double-blind, randomised controlled trial. Lancet. 2006;367:113-121.

70. Lunde K, Solheim S, Aakhus S, et al. Intracoronary injection of mononuclear bone marrow cells in acute myocardial infarction. $N$ Engl J Med. 2006; 355:1199-1209.

71. Schachinger V, Assmus B, Britten MB, et al. Transplantation of progenitor cells and regeneration enhancement in acute myocardial infarction: final oneyear results of the TOPCARE-AMI Trial. J Am Coll Cardiol. 2004;44:16901699.

72. Fukushima S, Varela-Carver A, Coppen SR, et al. Direct intramyocardial but not intracoronary injection of bone marrow cells induces ventricular arrhythmias in a rat chronic ischemic heart failure model. Circulation. 2007;115:2254-2261.

73. Pak HN, Qayyum M, Kim DT, et al. Mesenchymal stem cell injection induces cardiac nerve sprouting and increased tenascin expression in a swine model of myocardial infarction. J Cardiovasc Electrophysiol. 2003;14:841-848.

74. Smits PC, van Geuns RJ, Poldermans D, et al. Catheter-based intramyocardial injection of autologous skeletal myoblasts as a primary treatment of ischemic heart failure: clinical experience with six-month follow-up. J Am Coll Cardiol. 2003;42:2063-2069.

75. Trzos E, Krzeminska-Pakula M, Rechcinski $T$, et al. The effects of intracoronary autologous mononuclear bone marrow cell transplantation on cardiac arrhythmia and heart rate variability. Kardiol Pol. 2009;67:713-721.

76. Abraham MR, Henrikson CA, Tung L, et al. Antiarrhythmic engineering of skeletal myoblasts for cardiac transplantation. Circ Res. 2005;97:159-167.

77. Chang MG, Tung L, Sekar RB, et al. Proarrhythmic potential of mesenchymal stem cell transplantation revealed in an in vitro coculture model. Circulation. 2006;113:1832-1841.

78. Swijnenburg RJ, Govaert JA, van der Bogt KE, et al. Timing of bone marrow cell delivery has minimal effects on cell viability and cardiac recovery after myocardial infarction. Circ Cardiovasc Imaging. 2010;3:77-85.

79. Li Z, Lee A, Huang M, et al. Imaging survival and function of transplanted cardiac resident stem cells. J Am Coll Cardiol. 2009;53:1229-1240.

80. van der Bogt KE, Schrepfer S, Yu J, et al. Comparison of transplantation of adipose tissue- and bone marrow-derived mesenchymal stem cells in the infarcted heart. Transplantation. 2009;87:642-652.

81. van der Bogt KE, Sheikh AY, Schrepfer S, et al. Comparison of different adult stem cell types for treatment of myocardial ischemia. Circulation. 2008;118(suppl):S121-S129.
82. Goussetis E, Manginas A, Koutelou M, et al. Intracoronary infusion of $\mathrm{CD} 133+$ and CD133-CD34+ selected autologous bone marrow progenitor cells in patients with chronic ischemic cardiomyopathy: cell isolation, adherence to the infarcted area, and body distribution. Stem Cells. 2006;24: 2279-2283.

83. Hofmann M, Wollert KC, Meyer GP, et al. Monitoring of bone marrow cell homing into the infarcted human myocardium. Circulation. 2005;111:21982202.

84. Terrovitis J, Kwok KF, Lautamaki R, et al. Ectopic expression of the sodiumiodide symporter enables imaging of transplanted cardiac stem cells in vivo by single-photon emission computed tomography or positron emission tomography. J Am Coll Cardiol. 2008;52:1652-1660.

85. Bonios M, Terrovitis J, O'Rourke B, et al. Myocardial substrate determines acute cardiac retention and lung biodistribution of intramyocardially injected cardiac-derived stem cells: a PET/CT experimental study [abstract]. Circulation. 2008;118(suppl):645.

86. Terrovitis J, Lautamaki R, Bonios M, et al. Noninvasive quantification and optimization of acute cell retention by in vivo positron emission tomography after intramyocardial cardiac-derived stem cell delivery. J Am Coll Cardiol. 2009;54:1619-1626.

87. Dohan O, De la Vieja A, Paroder V, et al. The sodium/iodide symporter (NIS): characterization, regulation, and medical significance. Endocr Rev. 2003;24: 48-77.

88. Xie X, Cao F, Sheikh AY, et al. Genetic modification of embryonic stem cells with VEGF enhances cell survival and improves cardiac function. Cloning Stem Cells. 2007;9:549-563.

89. Leor J, Gerecht S, Cohen S, et al. Human embryonic stem cell transplantation to repair the infarcted myocardium. Heart. 2007;93:1278-1284.

90. Li Z, Suzuki Y, Huang M, et al. Comparison of reporter gene and iron particle labeling for tracking fate of human embryonic stem cells and differentiated endothelial cells in living subjects. Stem Cells. 2008;26:864-873.

91. Swijnenburg RJ, van der Bogt KE, Sheikh AY, Cao F, Wu JC. Clinical hurdles for the transplantation of cardiomyocytes derived from human embryonic stem cells: role of molecular imaging. Curr Opin Biotechnol. 2007;18:38-45.

92. Boyd AS, Higashi Y, Wood KJ. Transplanting stem cells: potential targets for immune attack-modulating the immune response against embryonic stem cell transplantation. Adv Drug Deliv Rev. 2005;57:1944-1969.

93. Guidance for Industry: Regulation of Human Cells, Tissues, and Cellular and Tissue-Based Products (HCT/Ps) — Small Entity Compliance Guide. Available at: http://www.fda.gov/BiologicsBloodVaccines/GuidanceCompliance RegulatoryInformation/Guidances/Tissue/ucm073366.htm. Accessed February 14, 2010.

94. Fernandez-Aviles F, San Roman JA, Garcia-Frade J, et al. Experimental and clinical regenerative capability of human bone marrow cells after myocardial infarction. Circ Res. 2004;95:742-748.

95. Bartunek J, Vanderheyden M, Vandekerckhove B, et al. Intracoronary injection of CD133-positive enriched bone marrow progenitor cells promotes cardiac recovery after recent myocardial infarction: feasibility and safety. Circulation. 2005;112(9, suppl):I178-I183.

96. Silva GV, Perin EC, Dohmann HF, et al. Catheter-based transendocardial delivery of autologous bone-marrow-derived mononuclear cells in patients listed for heart transplantation. Tex Heart Inst J. 2004;31:214-219.

97. Perin EC, Dohmann HF, Borojevic R, et al. Improved exercise capacity and ischemia 6 and 12 months after transendocardial injection of autologous bone marrow mononuclear cells for ischemic cardiomyopathy. Circulation. 2004;110(11, suppl 1):II213-II218.

98. Lim F, Sun AM. Microencapsulated islets as bioartificial endocrine pancreas. Science. 1980;210:908-910.

99. Barnett BP, Arepally A, Karmarkar PV, et al. Magnetic resonance-guided, realtime targeted delivery and imaging of magnetocapsules immunoprotecting pancreatic islet cells. Nat Med. 2007;13:986-991.

100. Kraitchman DL, Bulte JW. In vivo imaging of stem cells and beta cells using direct cell labeling and reporter gene methods. Arterioscler Thromb Vasc Biol. 2009;29:1025-1030.

101. Tsui BM, Kraitchman DL. Recent advances in small-animal cardiovascular imaging. J Nucl Med. 2009;50:667-670.

102. Barnett BP, Kraitchman DL, Lauzon C, et al. Radiopaque alginate microcapsules for x-ray visualization and immunoprotection of cellular therapeutics. Mol Pharm. 2006;3:531-538.

103. Willmann JK, Paulmurugan R, Rodriguez-Porcel M, et al. Imaging gene expression in human mesenchymal stem cells: from small to large animals. Radiology. 2009;252:117-127. 